\title{
Effects of cyclic steroid hormone replacement on prolactin and luteinizing hormone surges in female rats
}

\author{
A M Brown, J M Janik, E S Murphree ${ }^{1}$, R King and P Callahan \\ Center for Neuroscience, Department of Zoology and ${ }^{1}$ Department of Mathematics and Statistics, \\ Miami University, Oxford, Ohio 45056, USA \\ Correspondence should be addressed to P Callahan; Email: Callahp@muohio.edu
}

\begin{abstract}
The ability of steroid hormones to produce an LH or prolactin (PRL) surge was determined in rats ovariectomized at 6, 9 or 13 weeks of age and subjected to one, three or six cycles of estrogen and progesterone replacement. Sensitivity to steroid replacement was dependent on the age of the animal at the time of ovariectomy. Repeated cyclic steroid hormone replacement significantly increased the magnitude of the PRL response, but not the LH response, in animals ovariectomized at 6 weeks. The LH response was significantly altered by cyclic steroid replacement only in animals ovariectomized at 13 weeks. These results indicate that the mechanisms involved in the regulation of PRL secretion are influenced by steroid hormone replacement and that cyclic steroid hormone exposure increases the magnitude of the PRL secretory response.

Reproduction (2004) 128 373-378
\end{abstract}

\section{Introduction}

Puberty is a complex process during which the prepubescent female progresses into a reproductively mature state, marking the onset of regular cyclicity and ovulation. A number of neural changes occur during embryonic and prepubertal development that permit activation of gonadotropin-releasing hormone $(\mathrm{GnRH})$ neurons, and therefore the onset of puberty (see Gore 2002 for review). Circulating gonadal steroid levels gradually rise as $\mathrm{GnRH}$ pulse frequency and amplitude increase during pubertal development (Sisk et al. 2001), but puberty occurs due to $\mathrm{GnRH}$ neuronal activation, independent of gonadal steroids (see Gore 2002 for review).

A luteinizing hormone (LH) surge can be induced in mature ovariectomized females by several different methods, ranging from sequential injections of estrogen and progesterone (e.g. Hiemke et al. 1987, Bonavera et al. 1993) to steroid implants (e.g. Le et al. 1997, Yen \& Pan 1998). Simultaneous treatment with both estrogen and progesterone appears to suppress the steroid-induced $\mathrm{LH}$ surge (Legan et al. 1973, McPherson et al. 1975, Attardi 1981). One limitation of administering steroids by implanting pellets is that constant high levels of estrogen and/or progesterone desensitize the pituitary gland to subsequent estrogen or GnRH stimulation (for review see Gharib et al. 1990). The method that most closely resembles the estrous cycle of the rat (estrogen followed by progesterone replacement $1-3$ days later) is effective at producing an LH surge in the mature female rat from 1 day to 8 weeks after ovariectomy (Legan et al. 1973, Caligaris et al. 1974, Blake 1977, Adler et al. 1983, Clough \& Rodriguez-Sierra 1983, Rubin et al. 1985, Pi 1986, Bonavera et al. 1993). The interval between ovariectomy and steroid replacement is important, because after ovariectomy, circulating gonadotropin levels rise due to the decline in steroid hormones. This causes the pituitary gland to become more responsive to $\mathrm{GnRH}$ (Legan et al. 1973), resulting in a higher LH peak response to estrogen and progesterone treatment over time. Furthermore, King \& Letourneau (1994) reported that by 3 weeks post-ovariectomy, the sex differences in GnRH terminals in intact male and female rats no longer existed and the percentage of $\mathrm{GnRH}$ terminals containing $\mathrm{GnRH}$ decreased.

The aim of this study was to determine if the age of female rats at the time of ovariectomy affected the magnitude of the prolactin (PRL) or LH surge induced by steroid hormone replacement. Steroids were administered to rats ovariectomized at 6, 9 or 13 weeks of age. We hypothesized that age at ovariectomy would not influence the magnitude of the LH or PRL surge when repeated cyclic steroid hormone replacement was given.

\section{Materials and Methods}

\section{Animals and treatments}

Female rats (Ratus ratus) of the Sprague-Dawley strain were purchased from Harlan Laboratories (Indianapolis, 
IN, USA). All rats were ovariectomized. The ages of rats at the time of ovariectomy were: 6 weeks (puberty was initiated and all animals had vaginal opening), 9 weeks (pubescent), or 13 weeks (mature). All animals were housed in the animal facility at Miami University on a $12 \mathrm{~h}$ light: $12 \mathrm{~h}$ darkness cycle (lights on at $0700 \mathrm{~h}$ ). Food and water were freely available. All procedures were performed in accordance with the National Institutes of Health (NIH) guidelines and were approved by the Miami University Institutional Animal Care and Use Committee (IACUC).

Bilateral ovariectomies were performed under isoflurane/oxygen gas anesthesia. Following a 7-day recovery period, rats were injected with $17-\beta$-estradiol $(50 \mu \mathrm{g} / \mathrm{kg}$, s.c.) at $1000 \mathrm{~h}$ (day 1). Two days later (day 3), animals received progesterone $(2.5 \mathrm{mg} / \mathrm{kg}$, s.c.) at $1000 \mathrm{~h}$. Animals receiving a single cycle of steroid hormones were used in experiments on day 3 . Animals receiving multiple cycles did not receive any steroids for 2 days (days 4 and 5) and the injection schedule was then repeated starting on day 6. This steroid replacement regimen was designed to mimic the 5-day estrous cycle. Animals from each age group received either one, three or six consecutive cycles of steroid replacement following this same injection procedure. Steroids were solubilized in sesame oil, and were purchased from Sigma.

The day after the final estrogen injection, in-dwelling jugular catheters were surgically implanted in each rat under isoflurane/oxygen gas anesthesia as previously described (Bryant et al. 1998). The following day, each rat received a final progesterone injection at $1000 \mathrm{~h}$ and blood samples were withdrawn at 1200, 1400, 1500, 1600, 1700, 1900 and $2100 \mathrm{~h}$. Blood volume was immediately replaced with an equal volume of sterile, heparinized $(50 \mathrm{U} / \mathrm{ml})$ saline. Following the last blood sample, rats were killed. All blood samples were stored at $4{ }^{\circ} \mathrm{C}$ until centrifuged $(1000 \mathrm{~g})$. Plasma was collected and stored at $-20^{\circ} \mathrm{C}$ until subjected to radioimmunoassay.

Immediately after the rats had been killed $(2100 \mathrm{~h})$, the uterus (including the cervix) was removed from each rat and the fat was removed. Uteri were blotted on absorbent paper, and wet uterine weights were recorded. Wet uterine weights are reported as a percentage of body weight.

\section{Radioimmunoassay}

Plasma samples were assayed in duplicate for LH and PRL using reagents provided by the National Hormone and Peptide Program (NHPP), the National Institute of Diabetes and Digestive and Kidney Diseases (NIDDK), and Dr A F Parlow. Hormone levels were expressed in terms of rat PRL RP-3 or rat LH RP-3. Goat anti-rat gamma globulin was purchased from Antibodies Inc. (Davis, CA, USA) and ${ }^{125}$ I-labeled PRL or ${ }^{125}$ I-labeled $\mathrm{LH}$ was obtained from Covance Laboratories (Vienna, VA, USA). Intraassay and interassay coefficients of variation were less than $4 \%$ and $7 \%$ respectively.

\section{Statistical analysis}

Data for serial $\mathrm{LH}$ and PRL levels, and wet uterine weight/body weight, were analyzed using a repeated measures ANOVA. Maximum LH and PRL levels were defined as the highest respective hormone levels between 1400 and $1900 \mathrm{~h}$. For consistency, a 'surge' in LH or PRL was achieved if that value exceeded the group mean basal level by more than six standard deviations (surge $>$ mean $_{\text {basal levels }}+6$ s. D. basal levels). Group means were compared using a Bonferroni multiple comparison $t$-test and overall error rates were controlled at $\alpha=0.05$. The relationship between the number of cycles of steroid hormone replacement and the tendency to reach surge levels was analyzed using Fisher's exact test for categorical data. All statistical analyses were performed on the Miami University SAS system.

\section{Results}

Multiple cycles of steroid replacement significantly increased the maximum PRL levels in females ovariectomized at 6 weeks, as well as the maximum LH level in females ovariectomized at 13 weeks (Table 1). In females ovariectomized at 6 weeks, maximum PRL levels were significantly higher following six cycles of steroid replacement compared with one cycle $(P=0.0001)$. The probability that steroids induced a PRL surge was greater following multiple cycles of replacement only in animals ovariectomized at 6 weeks $(P=0.0357)$ (Table 2). Multiple cycles of steroid treatment increased maximum $\mathrm{LH}$ levels only in females ovariectomized at 13 weeks, with a significant increase occurring after three cycles of estrogen and progesterone $(E+P)$ compared with one $(P=0.0019)$ and six cycles $(P=0.0003)$ (Table 1$)$. The probability that multiple cycles of steroid replacement would induce an LH surge was not significantly affected by age of the animal at the time of ovariectomy. There were no significant differences in basal levels of LH or PRL between steroidreplaced and non-treated animals. Basal LH levels in nonsteroid-treated animals ranged from 8.3 to $42 \mathrm{ng} / \mathrm{ml}$ (mean, $25.5 \pm 14.6$ ). Basal PRL levels in non-steroid-treated animals ranged from 0.8 to $12.47 \mathrm{ng} / \mathrm{ml}$ (mean, $3.29 \pm 2.95)$.

\section{Ovariectomy at 6 weeks}

Only one of five females ovariectomized at 6 weeks of age had a significant LH or PRL surge following one cycle of $E+P$ replacement and the PRL surge was very high (Fig. 1, Table 2). Following three consecutive $\mathrm{E}+\mathrm{P}$ treatments, two of six rats showed an LH surge, while four had a significant PRL surge. After receiving six cycles of $\mathrm{E}+\mathrm{P}$, only three of five rats $(60 \%)$ had an $\mathrm{LH}$ surge, but all of these animals had a PRL surge. Representative $\mathrm{LH}$ and PRL surges for each treatment group are shown in Fig. 1. 
Table $1 \mathrm{LH}$ and PRL levels in female rats following steroid replacement.

\begin{tabular}{|c|c|c|c|c|c|}
\hline $\begin{array}{l}\text { Age at OVX } \\
\text { (weeks) }\end{array}$ & $\begin{array}{c}\mathbf{E}+\mathbf{P} \text { replacement } \\
\text { (no. of cycles) }\end{array}$ & $\begin{array}{l}\text { LH basal level } \\
\qquad(\mathrm{ng} / \mathrm{ml})\end{array}$ & $\begin{array}{l}\text { LH surge level } \\
\qquad(\mathrm{ng} / \mathrm{ml})\end{array}$ & $\begin{array}{l}\text { PRL basal level } \\
(\mathrm{ng} / \mathrm{ml})\end{array}$ & $\begin{array}{c}\text { PRL surge level } \\
(\mathrm{ng} / \mathrm{ml})\end{array}$ \\
\hline $6(n=5)$ & 1 & $7.7 \pm 1.3$ & $18.7 \pm 42.6$ & $2.0 \pm 0.7$ & $37.1 \pm 54.6$ \\
\hline $6(n=6)$ & 3 & $8.9 \pm 1.8$ & $80.2 \pm 38.9$ & $11.8 \pm 5.0$ & $216.0 \pm 49.8$ \\
\hline $6(n=5)$ & 6 & $9.2 \pm 2.1$ & $90.5 \pm 42.6$ & $10.8 \pm 6.8$ & $450.0 \pm 54.6 *$ \\
\hline $9(n=6)$ & 1 & $7.5 \pm 1.7$ & $13.5 \pm 38.9$ & $4.1 \pm 0.4$ & $76.5 \pm 49.8$ \\
\hline $9(n=6)$ & 3 & $11.4 \pm 2.9$ & $43.6 \pm 38.9$ & $5.5 \pm 1.4$ & $157.6 \pm 49.8$ \\
\hline $9(n=5)$ & 6 & $13.9 \pm 2.0$ & $21.8 \pm 42.6$ & $6.4 \pm 1.8$ & $230.2 \pm 54.6$ \\
\hline $13(n=7)$ & 1 & $12.0 \pm 1.8$ & $32.8 \pm 36.0$ & $4.2 \pm 3.2$ & $186.0 \pm 46.1$ \\
\hline $13(n=5)$ & 3 & $31.0 \pm 6.3$ & $163.1 \pm 38.9+$ & $22.4 \pm 10.4$ & $253.9 \pm 49.8$ \\
\hline $13(n=8)$ & 6 & $15.9 \pm 3.4$ & $19.8 \pm 14.7$ & $17.1 \pm 7.6$ & $208.1 \pm 66.5$ \\
\hline
\end{tabular}

$n$, number of animals in each treatment group.

$*$ In females ovariectomized (OVX) at 6 weeks, six cycles of E + P produced a significant increase in maximum PRL levels compared to animals receiving one cycle $(P=0.0001)$.

+In females ovariectomized at 13 weeks, maximum levels of LH following three cycles of steroid replacement was greater than after either one $(P=0.0019)$ or $\operatorname{six}(P=0.0003)$ cycles.

\section{Ovariectomy at 9 weeks}

One cycle of steroid hormone replacement did not induce an LH surge in any animal ovariectomized at 6 weeks of age. However, after three or six cycles of steroid replacement, some animals had a significant increase in LH. Only one female had an LH surge after six cycles of steroid hormones and this surge occurred earlier than expected. Significant PRL surges were observed in some animals in all treatment groups. See Fig. 2 for representative $\mathrm{LH}$ and PRL surges in animals ovariectomized at 9 weeks of age (see also Table 2).

\section{Ovariectomy at 13 weeks}

Only one of seven rats that received a single cycle of $\mathrm{E}+\mathrm{P}$ exhibited an $\mathrm{LH}$ surge, whereas four animals in this group had PRL surges. After receiving three cycles of $\mathrm{E}+\mathrm{P}, 60 \%$ had an LH surge, and all rats had a PRL surge. When females received six cycles of $E+P$, six of eight rats had a PRL surge, but none had an LH surge.

Table 2 Summary of the effects of repeated cycles of steroid replacement on the $\mathrm{LH}$ and PRL surges $(\mathrm{ng} / \mathrm{ml})$ in female rats ovariectomized at different ages.

\begin{tabular}{lccc}
\hline $\begin{array}{l}\text { Age at } \\
\text { OVX } \\
\text { (weeks) }\end{array}$ & $\begin{array}{c}\text { E + P replacement } \\
\text { (no. of cycles) }\end{array}$ & $\begin{array}{c}\text { No. of animals } \\
\text { exhibiting } \\
\text { LH surge }\end{array}$ & $\begin{array}{c}\text { No. of animals } \\
\text { exhibiting } \\
\text { PRL surge* }\end{array}$ \\
\hline 6 & 1 & $1 / 5(20 \%)$ & $1 / 5(20 \%)$ \\
6 & 3 & $2 / 6(33 \%)$ & $4 / 6(67 \%)$ \\
6 & 6 & $3 / 5(60 \%)$ & $5 / 5(100 \%)$ \\
9 & 1 & $0 / 6(0 \%)$ & $5 / 6(83 \%)$ \\
9 & 3 & $2 / 5(40 \%)$ & $3 / 5(60 \%)$ \\
9 & 6 & $1 / 5(20 \%)$ & $4 / 5(80 \%)$ \\
13 & 1 & $1 / 7(14 \%)$ & $4 / 7(57 \%)$ \\
13 & 3 & $3 / 5(60 \%)$ & $5 / 5(100 \%)$ \\
13 & 6 & $0 / 8(0 \%)$ & $6 / 8(75 \%)$ \\
\hline
\end{tabular}

* There was a greater probability $(P=0.0357)$ that PRL levels would reach defined surge values following multiple cycles of $E+P$ in females ovariectomized (OVX) at 6 weeks.
Representative LH and PRL surges are shown in Fig. 3 (see also Table 2).

It is important to note that in every case, regardless of age or treatment, females that had an $\mathrm{LH}$ surge also had a concomitant PRL surge; however, many animals had a PRL surge without a concomitant LH surge.

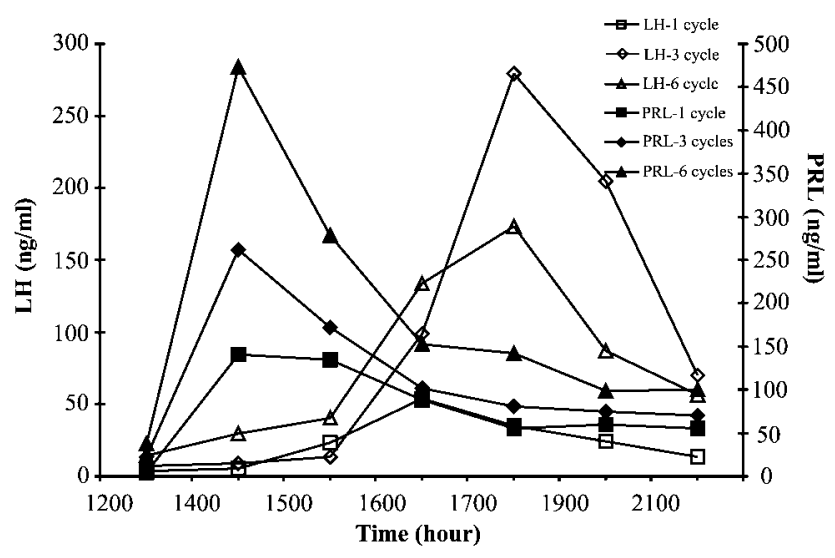

Figure 1 Representative LH and PRL levels in female Sprague-Dawley rats ovariectomized at 6 weeks of age and treated with one, three or six cycles of $\mathrm{E}+\mathrm{P}$.

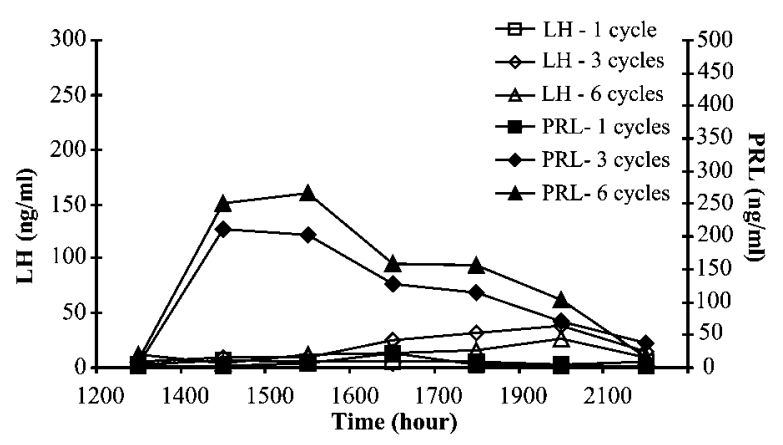

Figure 2 Representative LH and PRL levels in individual female Sprague-Dawley rats ovariectomized at 9 weeks of age and treated with one, three or six cycles of $\mathrm{E}+\mathrm{P}$. 


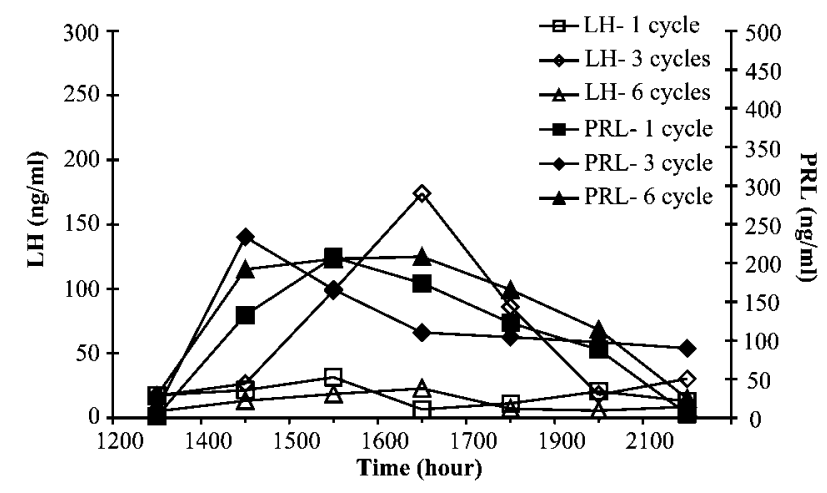

Figure 3 Representative LH and PRL levels in individual female Sprague-Dawley rats ovariectomized at 13 weeks of age and treated with one, three or six cycles of $\mathrm{E}+\mathrm{P}$.

\section{Wet uterine weight and body weight}

Body weight increased gradually with age in all groups (data not shown). Both age and the number of $E+P$ replacement cycles significantly affected wet uterine weight. Following three cycles of $\mathrm{E}+\mathrm{P}$ treatment, rats ovariectomized at 13 weeks showed a significant increase $(P=0.0001)$ in uterine weight over 6-week-old rats receiving the three cycles (Fig. 4). In addition, among rats ovariectomized at 13 weeks there was a significant increase in uterine weight after three cycles of steroid treatment compared with one $(P=0.0001)$ or six cycles $(P=0.0013)$.

\section{Discussion}

This study is the first to demonstrate that a PRL surge can be induced by steroids in young rats, and that the amplitude of the surge significantly increases with repeated cyclic exposure to steroids. Although $\mathrm{LH}$ levels showed a similarly increasing trend with age, this trend

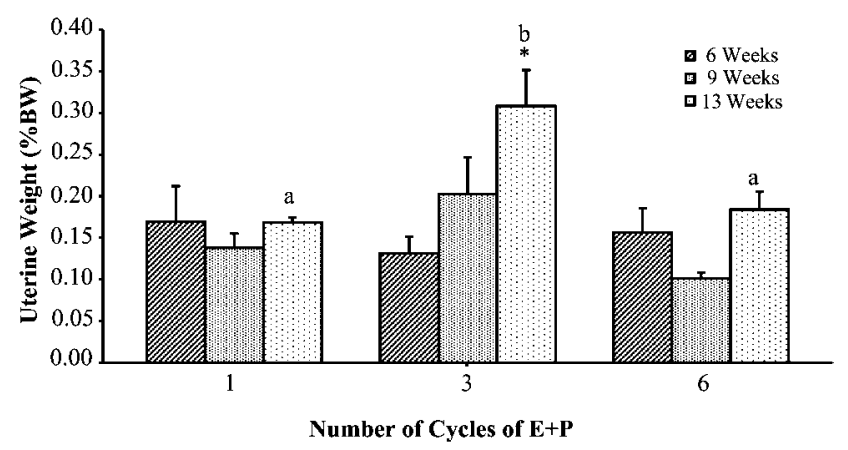

Figure 4 Wet uterine weight at the time of killing $(2100 \mathrm{~h})$ as a percentage of body weight for animals ovariectomized at 6,9 or 13 weeks of age and replaced with $\mathrm{E}+\mathrm{P}$ for one, three or six cycles. In rats ovariectomized at 13 weeks, there was a significant increase in uterine weight after three cycles of steroid treatment compared with one $(P=0.0001)$ or six cycles $(P=0.0013)$. Values with the same letter are not significantly different. *Significant increase $(P=0.0001)$ compared with 6-week-old rats receiving three cycles of $E+P$. was not significant. Wet uterine weight, an index of estrogen sensitivity in females (Ojeda et al. 1976), increased significantly with steroid treatment only in animals ovariectomized at 13 weeks.

Although the cyclic steroid replacement regimen used in this study was unique, the low doses of $E+P$ were similar to those used by others (Blake 1977, Hiemke \& Ghraf 1984, Rubin et al. 1985, Pi 1986, Hiemke et al. 1987, Lee et al. 1990, Bonavera et al. 1993). Adult females, regardless of the doses of $\mathrm{E}+\mathrm{P}$ administered, showed much larger LH surges (Blake 1977, Rubin et al. 1985, Pi 1986, Lee et al. 1990) than were observed in our study. In addition, dose and/or timing of steroid treatment, the age of the animal at ovariectomy (Adler et al. 1983, Clough \& Rodriguez-Sierra 1983) as well as the recovery period (Legan et al. 1973) were different. In agreement with our results, Aguan et al. (1996) reported that female rats ovariectomized at 10 weeks of age had low LH levels in response to steroid replacement, even when higher doses of $\mathrm{E}+\mathrm{P}$ were administered. Bonavera et al. (1993) also reported that $\mathrm{LH}$ surges were lower when doses of steroids were similar to those used in this study. PRL levels were not reported in any of the previous studies. Indeed, the only studies of the steroid-induced PRL surge in ovariectomized females were conducted in adults (Chen \& Meites 1970, Gudelsky et al. 1981, Steele \& Myers 1990, Mai et al. 1994, Yen \& Pan 1998) and results varied widely, with maximum PRL levels similar to, or larger than, those reported here.

The probability of repeated steroid treatment inducing a PRL surge increased significantly in females ovariectomized at 6 weeks. Steroid hormones are known to increase the secretory ability of individual lactotroph cells. When adult, ovariectomized female rats received $\mathrm{E}+\mathrm{P}$ replacement for 10-14 days, there was an increase in the number of lactotrophs that actively release PRL, as well as in the overall lactotroph cell number, and increased amounts of PRL were secreted by individual lactotrophs (Livingstone et al. 1998). We have found that pituitary cells from mature cycling females were more sensitive to angiotensin II stimulation of PRL release compared with young or aged females, or males of any age (Janik et al. 1997), suggesting that cyclic steroid exposure is important in the PRL response to secretagogues. GnRH may stimulate angiotensin II, thus contributing to increased PRL secretion (DePaul et al. 2000). The effects of steroids on lactotrophs at the time of puberty $(\sim 30$ days) (Gore 2002) have not been examined after cyclic steroid replacement, but may be cumulative with successive numbers of $\mathrm{E}+\mathrm{P}$ cycles.

The cyclic steroid replacement regimen used in this study prevented the post-ovariectomy rise in basal $\mathrm{LH}$ levels, indicating that the negative feedback control of estrogen was still maintained and that the high LH levels seen after this time were not artifacts of ovariectomy alone (Legan et al. 1973). The most responsive females were those ovariectomized at 13 weeks and subjected to three 
cycles of steroid replacement. Indeed, following six cycles of replacement, steroids did not induce an LH surge in any of the animals ovariectomized at this age. The reason for this loss of responsiveness is not known, but one possibility is that the pituitary and/or hypothalamus may lose sensitivity to steroids. LH-releasing hormone (LHRH) immunoreactivity (Rubin \& King 1994, 1995, Wise 1982), as well as c-fos nuclear expression in LHRH neurons (Lloyd et al. 1994, Rubin et al. 1994, 1995) decreased in middle-aged rats when regular cyclicity ceased. Although the rats used in our study were not middle-aged, the pattern of steroid replacement, while cyclic, is unlikely to mimic exactly the endogenous, cyclic patterns of secretion that occur in intact females. Furthermore, the only exposure to steroid hormones that these animals received was at doses sufficiently high to induce $\mathrm{LH}$ secretion (Blake 1977, Hiemke \& Ghraf 1984, Rubin et al. 1985, Pi 1986, Hiemke et al. 1987, Lee et al. 1990, Bonavera et al. 1993). With multiple exposures at this level, the hypothalamus and/or pituitary may lose sensitivity to stimulation. Interestingly, the increase in wet uterine weight following successive $\mathrm{E}+\mathrm{P}$ treatments was also most pronounced in animals ovariectomized at 13 weeks of age following three cycles of steroid replacement. These data suggest that by 13 weeks, the uterus is more responsive to steroid replacement and that the sensitivity decreases with greater exposure.

The $\mathrm{LH}$ response appeared to be less sensitive to steroid stimulation compared with the PRL response. All females in which a steroid-induced LH surge was detected also had a concomitant PRL surge, but females that had a PRL surge did not necessarily have a concomitant LH surge. This was not unexpected since the regulation of these hormones occurs through distinct neural pathways (Steele \& Myers 1990). The PRL surges that were generated without concomitant LH surges were not stress induced, because even more frequent blood sampling did not significantly alter circulating hormone levels (Fox \& Smith 1985) and similar blood sampling methods did not produce stressinduced PRL increases (Bryant et al. 1998).

In conclusion, this is the first report of the effects of cyclic steroid hormone replacement on LH and PRL levels in animals ovariectomized at different ages. As early as 6 weeks of age, the LH and PRL secretory systems are capable of producing surges in response to steroid hormones, and PRL, but not $\mathrm{LH}$, has a greater response to multiple cycles of $E+P$. Since puberty occurs due to $\mathrm{GnRH}$ neuronal activation, independent of gonadal steroids (see Gore 2002, for review), the neural mechanisms controlling LH release are not affected by steroids, but those involved in PRL regulation are influenced by steroid hormone replacement.

\section{Acknowledgements}

This work was supported by NIH grant DK54065-01 to P C and an Ohio Board of Regents grant to P C and J M J.

\section{References}

Adler BA, Johnson MD, Lynch CO \& Crowley WR 1983 Evidence that norepinephrine and epinephrine systems mediate the stimulatory effects of ovarian hormones on luteinizing hormone and luteinizing hormone-releasing hormone. Endocrinology 113 1431-1438.

Aguan K, Mahesh VB, Ping L, Bhat G \& Brann DW 1996 Evidence for a physiological role for nitric oxide in the regulation of the $\mathrm{LH}$ surge: effect of central administration of antisense oligonucleotides to nitric oxide synthase. Neuroendocrinology 64 449-455.

Attardi B 1981 Facilitation and inhibition of the estrogen-induced luteinizing hormone surge in the rat by progesterone: effects of cytoplasmic and nuclear estrogen receptors in the hypothalamuspreoptic area, pituitary, and uterus. Endocrinology $\mathbf{1 0 8}$ 1487-1496.

Blake CA 1977 Effects of estrogen and progesterone on luteinizing hormone release in ovariectomized rats. Endocrinology 101 $1122-1129$

Bonavera JJ, Sahu A, Kalra PS \& Kalra SP 1993 Evidence that nitric oxide may mediate the ovarian steroid-induced luteinizing hormone surge: involvement of excitatory amino acids. Endocrinology $1332481-2487$.

Bryant W, Janik J, Baumann M \& Callahan P 1998 Orphanin FQ stimulates prolactin and growth hormone release in male and female rats. Brain Research 807 228-233.

Caligaris L, Astrada JJ \& Taleisnik S 1974 Oestrogen and progesterone influence on the release of prolactin in ovariectomized rats. Journal of Endocrinology 60 205-215.

Chen CL \& Meites J 1970 Effects of estrogen and progesterone on serum and pituitary prolactin levels in ovariectomized rats. Endocrinology 86 503-505.

Clough RW \& Rodriguez-Sierra JF 1983 Synaptic changes in the hypothalamus of the prepubertal female rat administered estrogen. American Journal of Anatomy 167 205-214.

DePaul AL, Bonaterra M, Aoki A \& Torres AI 2000 Cellular and function interactions between gonadotrophs and lactotrophs in pituitary cell cultures. Medical Electron Microscopy 33 231-240.

Fox SR \& Smith MS 1985 Changes in the pulsatile pattern of luteinizing hormone secretion during the rat estrous cycle. Endocrinology 116 1485-1492.

Gharib SD, Wierman ME, Shupnik MA \& Chin WW 1990 Molecular biology of the pituitary gonadotropins. Endocrine Reviews $\mathbf{1 1}$ 177-199.

Gore AC $2002 \mathrm{GnRH}$ neurons change across the life cycle. In GnRH: The Master Molecule of Reproduction, pp 53-92. Boston, MA: Kluwer Academic Publishers.

Gudelsky GA, Nansel DD \& Porter JC 1981 Role of estrogen in the dopaminergic control of prolactin secretion. Endocrinology 108 440-444.

Hiemke C \& Ghraf R 1984 Re-establishment of stimulatory estradiol effects on lutenizing hormone secretion in long term ovariectomized rats. Brain Research 294 182-185.

Hiemke C, Schmid A, Buttner D \& Ghraf R 1987 Improved model for the induction of proestrus-like gonadotropin surges in longterm ovariectomized rats. Journal of Steroid Biochemistry $\mathbf{2 8}$ 357-359.

Janik J, Robinson E, Shen J \& Callahan P 1997 Effects of age and gender on the All-induced stimulation of prolactin release and inositol phosphate accumulation in rat anterior pituitary cells in vitro. Mechanisms of Ageing and Development 95 113-130.

King JC \& Letourneau RJ 1994 Luteinizing hormone-releasing hormone terminals in the median eminence of rats undergo dramatic changes after gonadectomy, as revealed by electron microscopic image analysis. Endocrinology 134 1340-1351.

Le WW, Attardi B, Berghorn KA, Blaustein J \& Hoffman GE 1997 Progesterone blockade of a luteinizing hormone surge blocks luteinizing hormone-releasing hormone fos activation and activation of its preoptic area afferents. Brain Research 778 272-280. 
Lee WS, Smith MS \& Hoffman GE 1990 Progesterone enhances the surge of luteinizing hormone by increasing the activation of luteinizing hormone-releasing hormone neurons. Endocrinology 127 2604-2606.

Legan SJ, Gay VL \& Midgley AR 1973 LH release following steroid administration in ovariectomized rats. Endocrinology 93 781-785.

Livingstone JD, Lerant A \& Freeman ME 1998 Ovarian steroids modulate responsiveness to dopamine and expression of G-proteins in lactotropes. Neuroendocrinology 68 172-179.

Lloyd JM, Hoffman GE \& Wise PM 1994 Decline in immediate early gene expression in gonadotrophin-releasing hormone neurons during proestrus in regularly cycling, middle aged rats. Endocrinology 134 1800-1805.

McPherson JC, Costoff A \& Mahesh VB 1975 Influence of estrogenprogesterone combinations on gonadotropin secretion in castrate female rats. Endocrinology 97 771-779.

Mai LM, Shieh KR \& Pan JT 1994 Circadian changes of serum prolactin levels and tuberoinfundibular dopaminergic neuron activities in ovariectomized rats treated with or without estrogen: the role of the suprachiasmatic nuclei. Neuroendocrinology 60 $520-526$.

Ojeda SR, Wheaton JE, Jameson HE \& McCann SM 1976 The onset of puberty in the female rat: changes in plasma prolactin, gonadotropins, luteinizing hormone-releasing hormone (LHRH), and hypothalamic LHRH content. Endocrinology 98 630-638.

Pi WP 1986 Effectiveness of estradiol and progesterone in inducing LH release in different stages in rat estrous cycles. Proceedings of the National Science Council 10 245-249.

Rubin BA \& King JC 1994 The number and distribution of detectable luteinizing hormone (LH)-releasing hormone cell bodies changes in association with the preovulatory LH surge in the brains of young but not middle-aged female rats. Endocrinology 134 467-474.

Rubin BA \& King JC 1995 A relative depletion of luteinizing hormone-releasing hormone was observed in the median eminence of young but not middle-aged rats on the evening of proestrus. Neuroendocrinology 62 259-269.

Rubin BS, Elkind-Hirsch K \& Bridges RS 1985 Hypothalamic LHRH in aging rats: effects of ovariectomy and steroid replacement. Neurobiology of Aging 6 309-315.

Rubin BA, Lee CE \& King JC 1994 A reduced proportion of luteinizing hormone (LH)-releasing hormone neurons express Fos protein during the preovulatory or steroid-induced LH surge in the middle aged rats. Biology of Reproduction 51 1264-1272.

Rubin BA, Mitchell S, Lee CE \& King JC 1995 Reconstructions of populations of luteinizing hormone releasing hormone neurons in young and middle-aged rats reveal progressive increases in subgroups expressing Fos protein on proestrus and age-related deficits. Endocrinology 136 3823-3830.

Sisk CL, Richardson HN, Chappell PE \& Levine JE 2001 In vivo gonadotropin-releasing hormone secretion in female rats during peripubertal development and on proestrus. Endocrinology 142 2929-2936.

Steele MK \& Myers LS 1990 In vivo studies on paracrine actions of pituitary angiotensin II in stimulating prolactin release in rats. American Journal of Physiology 258 E619-E624.

Wise PM 1982 Alterations in the proestrous pattern of median eminence $\mathrm{LHRH}$, serum LH, FSH, estradiol and progesterone concentrations in middle-aged rats. Life Sciences 31 165-173.

Yen SH \& Pan JT 1998 Progesterone advances the diurnal rhythm of tuberoinfundibular dopaminergic neuronal activity and the prolactin surge in ovariectomized, estrogen-primed rats and in intact proestrus rats. Endocrinology 139 1602-1609.

Received 7 November 2003

First decision 6 January 2004

Revised manuscript received 28 May 2004

Accepted 9 June 2004 